\title{
African elephants use plant odours to make foraging decisions across multiple spatial scales
}

\author{
Melissa H. Schmitt ${ }^{1,2}$, Adam Shuttleworth ${ }^{1}$, David Ward ${ }^{1,3}$, \\ and Adrian M. Shrader ${ }^{1,4}$
}

\footnotetext{
${ }^{1}$ School of Life Sciences, University of KwaZulu-Natal, Pietermaritzburg, South Africa

${ }^{2}$ Present address: South African Environmental Observation Network, Ndlovu Node, Phalaborwa, South Africa

${ }^{3}$ Present address: Biological Sciences, Kent State University, Ohio, USA

${ }^{4}$ Department of Zoology \& Entomology, University of Pretoria, Pretoria, South Africa
}

*Corresponding author and current address: South African Environmental Observation Network, Ndlovu Node, Private Bag X1021, Phalaborwa 1390, South Africa

E-mail address: missyschmitt@gmail.com, Melissa.h.schmitt@gmail.com (M.H. Schmitt)

Telephone number: +18056375861

School of Life Sciences, University of KwaZulu-Natal, Private Bag X01, Scottsville 3209, South Africa

South African Environmental Observation Network, Ndlovu Node, Private Bag X1021, Phalaborwa 1390, South Africa

Biological Sciences, Kent State University, Kent, OH 44242, USA

Department of Zoology \& Entomology, University of Pretoria, Private Bag X28, Pretoria 0028, South Africa

\section{Highlights}

- Plants emit odours that can reflect their chemical properties and identities.

- The use of plant odour in mammalian herbivore foraging decisions is not well known.

- Our study suggests that African elephants use plant odours to make diet choices.

- These decisions span across two spatial scales. 


\begin{abstract}
Mammalian herbivores are known to be extremely selective when foraging, but little is known about the mechanisms governing the selection of patches and, at a finer scale, particular plants. Visual examination and direct sampling of the vegetation have previously been suggested, but olfactory cues have seldom been considered. We examined the use of olfactory cues by foraging African elephants and asked whether they use plant odours to select particular patches or specific plants when making feeding decisions. Scent-based choice experiments between various preferred and non-preferred plants were conducted across two spatial scales (between plants and between patches). We used coupled gas chromatography-mass spectrometry (GC-MS) analysis of headspace extracts of volatile organic compounds (VOCs) emitted by the different plant species to explore similarities among the overall odour profiles of each species. We found that elephants select their preferred plant species across both spatial scales, likely cuing off the differences in plant odour profiles. The ability to differentiate between plant odours allows elephants to reduce their search time by allowing them to target preferred plant species both within a feeding station and between patches. This suggests that olfactory cues likely play an important role in driving herbivore foraging decisions across multiple spatial scales.
\end{abstract}

Key words: Diet selection, foraging, herbivory, olfaction, volatile organic compounds, Y-maze 


\section{Introduction}

Mammalian herbivores make a vast number of foraging decisions across a broad range of spatial scales (Senft et al., 1987). At a small scale, these herbivores can take thousands of bites per day (Illius \& Gordon, 1990). At larger scales, they can move across a number of plant communities on a daily basis (Senft et al., 1987), while also strategically moving around their environment on a seasonal basis (Shrader, Bell, Bertolli, \& Ward, 2012). Thus, herbivores are faced with a dynamic foraging environment, which they need to navigate effectively. Ultimately, both small and large-scale movements across the landscape are driven by foraging decisions, with the final goal of maximising nutritional intake rates (Senft et al., 1987; Shipley, 2007; Owen-Smith, Fryxell, \& Merrill, 2010; Morgan, Hurly, Martin, \& Healy, 2016). However, a key question that remains unanswered is, "what cues do herbivores use to make foraging decisions across these different scales?"

Across a landscape, the abundance and distribution of plants vary spatially and, to a lesser extent, temporally (Ward, 1992; Wilmshurst, Fryxell, \& Hudson, 1995; Klaassen, Nolet, van Gils, \& Bauer, 2006; Ward, 2010). Plant species and individuals within a species can vary in nutritional composition and defence investment (Coley, Bryant, \& Chapin III, 1985; Harborne, 1991). Nutritional and structural composition can be beneficial (e.g. crude protein, digestibility) and detrimental (e.g. fibre, lignin), while investment in defences can be chemical (e.g. secondary metabolites, such as tannins, terpenes and alkaloids) (Freeland \& Janzen, 1974; Rhoades, 1979; Bell, 2012) or physical (Ward, Shrestha, \& Golan-Goldhirsh, 2012; Kariñho-Betancourt, Agrawal, Halitschke, \& Núñez- Farfán, 2015). The differences in nutritional and structural composition are frequently correlated with the dietary preference for a plant species (Cooper \& Owen-Smith, 1985; Barton \& Koricheva, 2010; Shrader et al., 2012). 
While foraging, herbivores have to locate preferred food, which can be costly. Moving from patch to patch at random would likely increase search time and energy loss associated with travelling between patches compared to travelling in more directed movements (Charnov, 1976; Ward \& Saltz, 1994; Owen-Smith et al., 2010). Thus, herbivores should make informed decisions about how and where to feed. Moreover, they should forage in a manner that maximises their nutritional intake, and minimizes travel costs (Pyke, Pulliam, \& Charnov, 1977; Owen-Smith et al., 2010; Houston \& McNamara, 2014). However, when faced with imperfect knowledge about the abundance and distribution of resources, what mechanisms do herbivores use to reduce search time and thus improve foraging choices and, ultimately, energy gain?

One way herbivores could do this is by continuously sampling forage to update information on nutritional quality (Krebs \& McCleery, 1984; Ruedenauer, Spaethe, \& Leonhardt, 2016). However, to obtain adequate information on a wide range of plant species, herbivores would need to sample large portions of the landscape throughout the year, which could result in increased travel costs. A second option would be to use visual cues. However, variation in visual acuity and colour detection among herbivore species (Entsu, Dohi, \& Yamada, 1992; Piggins \& Phillips, 1996; Jacobs, Deegan, \& Neitz, 1998) likely limit success in making dietary selections (Rutter, Orr, Yarrow, \& Champion, 2004). Moreover, visual cues can be easily obstructed by objects in the landscape, such as a preferred plant growing among a number of less preferred plants (Stutz, Banks, Dexter, \& McArthur, 2015).

Another option is for herbivores to use odours (volatile organic compounds: VOCs), which are emitted by all plants (Illius \& Gordon, 1993; Baluska \& Ninkovic, 2010). This has been well studied in insects (see: Bell, 1990; Raguso, 2008). However, the degree to which mammalian herbivores use odours when foraging is largely unknown (Provenza \& Balph, 
1987; Pietrzykowski, McArthur, Fitzgerald, \& Goodwin, 2003; Bedoya-Pérez, Isler, Banks, \& McArthur, 2014a).

Green leaves produce a variety of different volatiles including various aliphatics (especially green leaf volatiles) and terpenoids (including both monoterpenes and sesquiterpenes) (Peñuelas \& Llusià, 2004). These compounds are known to play various roles in plant signalling and defence but their importance for interactions with mammalian herbivores is not well explored (Bedoya-Pérez et al., 2014a). Furthermore, plant odours could be linked to preference for a particular item as a result of a conditioned response to past post-ingestive consequences (Villalba, Provenza, Catanese, \& Distel, 2015). For example, several studies have found that mammalian herbivores have learned to avoid certain plants due to negative postingestive feedback stemming from plant secondary metabolites (Provenza \& Balph, 1987; Provenza et al., 1990; Kyriazakis, Anderson, \& Duncan, 1998; Bedoya-Pérez et al., 2014a).

Due to the nature of VOCs that comprise odour profiles, plant odour likely can be detected from much greater distances than visual cues, and can pass through visually obstructing barriers (Bell, 2012; Stutz et al., 2015). While odour has the potential to be directed by the wind, and can be affected by temperature and light (Niinemets, Loreto, \& Reichstein, 2004), it can still be a useful tool for herbivores to detect preferred plant species across multiple spatial scales (Bell, 2012). Because odours can be emitted from distant patches, the use of plant odours by herbivores could reduce search time and energy expenditure while foraging (Bell, 2012).

Several recent studies (Stutz, Banks, Proschogo, \& McArthur, 2016; Finnerty, Stutz, Price, Banks, \& McArthur, 2017; Stutz, Croak, Proschogo, Banks, \& McArthur, 2018) have found that swamp wallabies use a combination of visual and olfactory cues to locate Eucalyptus seedlings from which to feed. These studies have focused on seedlings of the 
same species that either have differing nutritional qualities, or varying levels of concealment (both visual and olfactory). Results indicate that leaf odour influences wallaby foraging behaviour, which facilitates non-random searching for food (Stutz et al., 2016; Stutz et al., 2018). Yet, a key question not answered by these studies was whether mammalian herbivores use odour to differentiate between preferred and non-preferred plant species.

To explore the degree to which mammalian herbivores use plant odours to make foraging decisions across different spatial scales, we focused on the foraging of African elephants (Loxodonta africana). Due to their large body size, elephants have very high absolute nutritional requirements, necessitating a large number of foraging decisions within a day. Although they can tolerate a certain degree of low-quality vegetation, studies have indicated that they are extremely selective foragers (Owen-Smith \& Chafota, 2012; Pretorius et al., 2012). Elephants, like many other herbivores, forage in an environment where resources are often clustered in patches (Cohen, Pastor, \& Moen, 1999; De Knegt, Groen, Van De Vijver, Prins, \& Van Langevelde, 2008; Crane et al., 2016). As a result, they have to search and move through areas of low food availability, expending energy without gaining energy, to reach areas of higher resource availability. To forage in a nutritionally maximising and energetically efficient manner, elephants would need to make foraging decisions that reduce search time for preferred food items within and between these clusters.

Due to their keen sense of smell (Miller et al., 2015), we predicted that elephants are able to use plant odours to make foraging decisions. Furthermore, we predicted that the combination of plant species presented to elephants, as well as the difference in preference rank between plant species, would influence the elephant's foraging choice. We tested these predictions in choice experiments across two spatial scales. First, we tested if elephants could use olfactory cue to located preferred plant species at a fine spatial scale $(<0.5 \mathrm{~m})$, mimicking foraging decisions within a feeding station. Second, using a Y-maze to mimic between-patch 
choices, we determine if elephants could make between-patch foraging decisions using plant odours at a distance beyond their body length $(>7 \mathrm{~m})$.

\section{Methods}

All aspects of this research were approved by the institutional animal ethics committee (Reference number: AREC/106/015). To explore the role that odour plays in the foraging decisions of African elephants, we conducted two experiments. The first tested whether elephants used odour to make foraging decisions at the feeding-station scale $(<0.5 \mathrm{~m})$, and the second tested whether they use it at a larger spatial scale $(7 \mathrm{~m})$, which we considered to be equivalent to decisions made between two patches. Both experiments eliminated eyesight and touch as variables driving elephant foraging decisions and focused solely on scent.

All experiments were completed during August 2015 at the Adventures with Elephants facility near Bela Bela, Limpopo Province, South Africa. For all trials, professional elephant handlers were used to ensure the comfort and safety of the elephants. We used five semi-tame, wild foraging, sub-adult individuals between 15-20 years old (three females, two males) for the feeding-station experiment, and three of these same individuals (one female, two males) for the between-patches (Y-maze) experiment. We only used three individuals for the between-patch experiment because two of the elephants were unwilling to walk into the Y-maze. For both of these experiments, we were only interested in whether elephants used odour to make foraging decisions. Thus, we did not include sex as a variable in our analyses.

\section{Plant species}

A total of 12 woody plant species were utilized in our scent-based experiments (see below). Of these 12 species, six species comprised $75 \%$ of the elephants' diets at our study site as established by a previous study (Schmitt, Ward, \& Shrader, 2016). These 12 species were 
either categorized as "preferred" (including both preferred and principle species) or "nonpreferred" using an acceptability index (see below) (as per Owen-Smith \& Cooper, 1987). To obtain the acceptability index, we followed the free-ranging foraging elephants in their native habitats, at a distance of $\sim 50 \mathrm{~m}$. Along each feeding path, the abundance of every plant species present as well as the number of times a given plant species was consumed by an elephant was recorded along a series of $50 \mathrm{~m}$ long x $10 \mathrm{~m}$ wide belt transects ( $\mathrm{N}=100$ total). We chose a width of $5 \mathrm{~m}$ because this is the reach of a foraging elephant's trunk (Shrader et al., 2012). We also recorded all non-preferred species that were close to the chosen plant but not selected.

To generate the acceptability index (AI) of a species, the number of times a particular plant species was eaten was divided by the proportional abundance of that plant species in the same area (Owen-Smith \& Cooper, 1987). After compiling an index for every plant species present, we then identified the plant species that we consider to be "preferred" (both in its intrinsic meaning: i.e. most selected proportional to its abundance), as well as principal (i.e. selected overall most frequently - a function of acceptability and abundance), or "nonpreferred" (i.e. rarely eaten in relation to its abundance). Preferred plant species had AIs of $>0.5$ and non-preferred plant species had AIs below 0.3. Principal plant species were eaten the most frequently of all species encountered and had AIs ranging between $0.28-0.5$. For our study, we focused on six preferred and principal plant species that comprised $\sim 75 \%$ of the elephants' diets. These species were Pappea capensis (Sapindaceae), Dombeya rotundifolia (Malvaceae), Terminalia sericea (Combretaceae), Combretum zeyheri (Combretaceae), Grewia monticola (Malvaceae), and Euclea crispa (Ebenaceae). We also focused on the five most non-preferred plant species which were Vitex rehmannii (Lamiaceae), Searsia pyroides (Anacardiaceae), Searsia lancea (Anacardiaceae), Euclea undulata (Ebenaceae), and Olea europaea (Oleaceae). Additionally, we included a novel favourite, the combretum mistletoe 
Viscum combreticola (Santalaceae). This mistletoe was often out of reach for the elephants, and thus difficult to access. However, it was the most favoured species present at the study site (Appendix Table A1).

\section{Plant odour}

To verify that the odour profiles of the plants were different, we collected odour samples from vegetative parts (leaves and stems only) of each species used in the experiments $(n=8$ individual plants sampled per species). Leaves were left intact on the branch, with the branch still connected to the parent plant to ensure that we did not alter the odour profile while sampling. Volatile organic compounds (VOCs) were collected from each plant species using dynamic-headspace extraction methods (Tholl, 2006). This was done by enclosing a branch in a polyacetate bag (NaloPhan ${ }^{\circledR}$, Kalle, Germany) and extracting air from the bag for $3 \mathrm{~h}$ through a small cartridge filled with $1 \mathrm{mg}$ each of Tenax ${ }^{\circledR}$ TA (60/80) (SupelcoTM; Bellefonte, PA, USA) and Carbotrap ${ }^{\circledR}$ B (20-40 mesh) (Sigma-Aldrich Co.; St. Louis, MO, USA) using a PAS500 Personal Air Sampler (Spectrex, Redwood City, CA, USA). Control samples were collected for the same duration from empty polyacetate bags and used to identify environmental contaminants.

Volatiles were analysed by gas chromatography-mass spectrometry (GC-MS) using a Varian (Palo Alto, CA, USA) CP3800 gas chromatograph (fitted with a Varian 1079 injector with a ChromatoProbe thermal desorption device) coupled to a Varian 1200 quadrupole mass spectrometer. A polar (Bruker BR-Swax) capillary column was used. A detailed description of these methods is presented elsewhere (Shuttleworth \& Johnson, 2009). Compounds were identified using the NIST 2011 mass spectral library. In most cases, identifications were confirmed by comparison of retention times with published "Kovats" retention indices (Kovats, 1965) and/or injection of synthetic standards (for a complete table 
of VOCs identified, see Appendix Table A3). Absolute amounts of volatiles emitted were estimated by comparison of peak areas from samples with peak areas obtained from injection of a known amount of methyl benzoate (injected and run under identical conditions to samples) (Shuttleworth, 2016). It has previously been established that, for this analytical apparatus, methyl benzoate yields a peak area: nanogram (ng) relationship that is close to the average obtained from 200 compounds from various compound classes.

\section{Feeding-station experiment}

In the feeding-station experiment, we aimed to determine whether the elephants selected or avoided plant species in the same rank order in which they selected them in the field. We conducted a scent-based choice experiment using two identical $\sim 120 \mathrm{~L}$ black plastic bins placed side-by-side (Appendix Fig. A1). Each bin contained a branch from a single tree species. To ensure that only olfactory cues were available to the elephants, we inserted a PVC board into the side of each bin $\sim 10 \mathrm{~cm}$ from the top rim. This prevented the elephants from touching and seeing what was in each bin. The PVC board slid across the opening of the bin and fitted tightly around the edges of the interior (see Appendix Fig. A1). The board could be slid open once an elephant made its selection by indicating with its trunk when instructed to allow it to consume the item. To allow odour to waft out from inside the bin, we drilled $\sim 200$ small holes (1 cm diameter) through the PVC board.

To provide odours for the elephants to select between, we concealed a clipping of a favoured and/or non-preferred plant species harvested from the surrounding savanna inside each bin. We clipped branches to the equivalent size of an elephant's "small" trunkful ( $35 \mathrm{~g}$, see Schmitt et al., 2016) to standardize size across all trials. The clipped end of the plant was coated with Vaseline ${ }^{\circledR}$ to prevent emission of excess damage volatiles from the cut (Finnerty et al., 2017). We tested 11 species of plants (six preferred and five non-preferred) in a full 
factorial design with all 11 plant species being tested against each other, but not against themselves. This resulted in 55 combinations. Furthermore, we also included the combretum mistletoe (Viscum combreticola), which we tested against the most non-preferred (Olea europaea) and second-most non-preferred (Euclea undulata) plant species. This resulted in 57 combinations in total.

To ensure that the each elephant did not observe the experimental set-up during its trials, a professional handler instructed the elephants to face away $\left(180^{\circ}\right)$ from the testing arena. Once plant clippings were placed inside each bin, the bins were arranged side-by-side with the opening to the PVC grid facing away from where the elephant was standing. The elephant was then instructed to turn, face forward, and to "smell" the bins. At this point, the elephant would step up to the bins and place its trunk on each PVC board and inhale the odours from each patch (Appendix Fig. A1; Video 1). After sniffing both bins, the elephant was instructed to remove its trunk. We then instructed the elephant to "choose", at which point it placed its trunk in the preferred bin. To reinforce the choice, we gave the elephant the clipping to eat from inside of the selected bin. The bin that was not chosen was removed and the elephant was not allowed to see or eat the clipping within. This procedure was repeated five times consecutively for every elephant for each combination (we accounted for this serial correlation in our statistical analyses, see below). To ensure hunger levels did not influence diet selection, the elephants foraged naturally for one hour prior to testing. To account for potential selection bias based on what the herd of elephants encountered and fed on prior to trials, we randomly tested each combination per elephant throughout the experiment (i.e. each combination was given to an individual on different days). The position of each plant species, as well as the handler holding each bin (who also did not know the species in their bins), was randomized throughout the experiment by use of a random number generator. The experimenter was also blind to the position of each clipping. In addition, we cleaned the bins 
using water and a clean cloth prior to changing the plant species hidden inside to remove any residual odour. For photographic representation of the experiment, see Appendix Fig. A1.

\section{Between-patch experiment}

Based on the results of our previous experiment, we focused our between-patch selection experiment on only preferred versus non-preferred combinations because this is where the elephants showed significant differences in choice. In this experiment we aimed to determine:

(1) whether the elephants showed significant selection for the more preferred option across all combinations, and (2) to determine whether difference in rank between the two plant species influenced selection.

We used a Y-maze where elephants had to make a choice between two plant species over a $7 \mathrm{~m}$ distance. To further explore the preferred versus non-preferred category, we tested the following combinations: (1) the most preferred species (Pappea capensis) versus the most non-preferred (Olea europaea), (2) the most preferred species (Pappea capensis) versus the second-most non-preferred (Euclea undulata), (3) the novel most-preferred species (Viscum combreticola) versus the most non-preferred (Olea europaea), (4) the novel most-preferred species (Viscum combreticola) versus the second-most non-preferred (Euclea undulata), (5) the lowest ranked of the preferred species (Euclea crispa) versus the most non-preferred species (Olea europaea), and (6) the lowest ranked of the preferred species (Euclea crispa) versus the highest ranked of the non-preferred species (Vitex rehmannii).

For the between-patch experiment, we built one of the world's largest Y-mazes (see also: Hosoi, Rittenhouse, Swift, \& Richards, 1995), which was large enough for a large male elephant to walk through (for schematic, see Appendix Fig. A2). The height of the maze was $2.5 \mathrm{~m}$, and the walkways were $2.5 \mathrm{~m}$ wide, which was $>1 \mathrm{~m}$ wider than the elephants used in our study. The entrance into the $\mathrm{Y}$ was $1.5 \mathrm{~m}$ long, and each arm was $4 \mathrm{~m}$ in length. Because 
the elephants had to be able to get out of the Y-maze, we left the end of each arm open, but included a small $1.5 \mathrm{~m} \times 1.5 \mathrm{~m}$ chamber off the side end of each arm that housed the small trunkful of the food item in the far corner (which the elephant could not see) (Figure 2). To ensure the elephants were able to smell the plant samples from the start of the maze, we placed a fan in each of the chambers behind the plants, which blew the plant odours down each arm of the Y-maze.

At the start of the experiment, each elephant was instructed to stand at the start of the maze and smell down each arm (i.e. $~ 7 \mathrm{~m}$ from the plants; Appendix Fig. A2; Video 2). After the elephant smelled each arm of the Y-maze for $\sim 2 \mathrm{~s}$, it was instructed by their handlers to "choose". At that point, they walked down one arm of the Y-maze and were able to consume the plant sample in the small chamber at the end. To avoid bias and odour contamination, all observers and handlers stood directly behind the elephant, and no person walked through the arms of the Y-maze, or stood at the end of the Y-maze. This experiment was repeated 10 times per individual elephant per combination. We used a random number generator to randomize the side we placed each plant species. To ensure that there was no failure due to the dissipation of the plant odours, Y-maze trials were only conducted on windless mornings.

\section{Statistical methods}

\section{Plant odour}

We used a pairwise one-way ANOSIM randomization test (Anderson, 2001) to examine differences in odour between the 57 combinations of the preferred and non-preferred plant species. ANOSIM calculates the test statistic R, which is a relative measure of the separation between previously defined groups (e.g. preferred vs non-preferred plant species), based on differences of mean rank similarities between and within groups. $\mathrm{R}$ can range between 0 and 1, with 0 indicating completely random groupings (i.e. preferred and non-preferred plants do 
not exhibit different odours) and 1 indicating that samples within groups (e.g. preferred vs non-preferred species) are more similar to each other than to any samples from a different group (i.e. preferred and non-preferred plants exhibit different odours) (Clark et al., 2007). We used 10,000 random permutations of the grouping vector (preferred vs non-preferred) based on Euclidean distances to obtain an empirical distribution of $\mathrm{R}$ under the null hypothesis to establish significance using Primer v. 6 (Anderson, 2001).

\section{Behavioural choice}

Both the species-choice and the between-patch selection experiments involved a series of binary choices (i.e. two bins, or each arm of the Y-maze). Because we used the same elephants within each of our experiments, we treated individuals as the subjects for repeated measures in generalized estimating equations (GEEs). GEEs were used because of potential non-independence of our data, which could stem from an individual possibly remembering previous trials. We used GEEs because they use a population-level approach based on a quasi-likelihood function, they deliver population-averaged estimates of the parameters, and the coefficients of GEE regressions are marginal effects (i.e. the effects average across all the subjects in the data) (see Wang, 2014). Thus, in our case, GEEs model the proportion of elephants that make a given choice and compare this to an expected 50\% distribution expected under random selection for a given choice. The model incorporated an exchangeable correlation matrix, and binomial error distribution with a logit link function. Data were then back-transformed from the logit-scale for graphical representation. This backtransformation resulted in asymmetrical confidence intervals (CIs) (Hardin, 2005).

To determine if the elephants differentiated between the plant species at the feedingstation scale (i.e. bin experiment) based on plant odour, we analysed the proportion of elephants that chose the more preferred plant species (as described in our acceptability 
index). We used means and their 95\% CIs to establish whether the elephants' preference between the plant species differed from the expected 50\% distribution under random selection for each plant available. For the feeding-station scale (bin experiment), GEEs were utilized to determine (1) whether the elephants showed significant preference for the more preferred option across all combinations of the different plants that elephants encountered, (2) the role that combination type (i.e. two preferred species, two non-preferred species, or one preferred and one non-preferred species) played in diet choice, and (3) whether difference in rank between the two plant species (calculated from the acceptability indices) influenced diet choice.

We used elephant choice as the Boolean response variable. When species were from the same category (preferred vs preferred, or non-preferred vs non-preferred), preference was based on the acceptability index as outlined above. In separate GEEs, we tested the factors of combination (i.e. which species comprise a combination), combination type (i.e. two preferred species tested against each other, two non-preferred species tested against each other, or one preferred and one non-preferred species tested against each other), and difference in rank as independent variables with choice as the response variable. We could not run an interaction effect between combination type and difference in rank because not all combinations used all possible differences in rank (e.g. two preferred/ non-preferred options can never be a rank difference of $\geq 7$, whereas preferred vs non-preferred can range from 1 $13)$.

To explore whether elephants use scent to make foraging decisions between patches (i.e. using the Y-maze), we used GEEs to determine (1) whether the elephants showed significant preference for the more preferred plant species across all combinations, and (2) whether difference in rank between the two plant species influenced diet choice. All combinations in this experiment comprised one preferred species and one non-preferred 
species, so we did not explore the influence of combination type for this experiment. We used elephant choice as the Boolean response variable. In separate models, we tested the factors of combination (i.e. which plant species comprise a combination), and difference in rank.

\section{Results}

\section{Plant odour}

Analyses of the volatile organic compounds (i.e. odour profiles) from each plant species revealed that each species had a detectable and unique odour. The actual scent data (specific VOCs) are not presented here (Schmitt et al. unpublished data). We present a measure of the similarity between plant species' odour profiles only. Results from our pairwise ANOSIM indicate that all pairs of plant species had significantly different odour profiles, although some pairs exhibited low $\mathrm{R}$ values, suggesting that differences were less clear in these combinations (Appendix Table A2). This suggests that elephants could potentially differentiate between plant species by odour alone. Interestingly, pairwise comparisons between the odours of preferred plant species yielded low R values, while comparisons of the odour of preferred species with that of non-preferred species and comparisons between nonpreferred species yielded higher R values (Appendix Table A2). This suggests greater similarity between the odours of preferred species, greater differences between preferred and non-preferred, and between non-preferred species (Appendix Table A2).

\section{Feeding-station experiment}

The combination of plant species presented to the elephants significantly influenced their choice (GEE: $\left.\chi^{2}=789.957, P<0.0001\right)$. Across all 57 combinations, elephants selected for their preferred species $\sim 63 \%$ of the time, and showed no preference between the two options 
$\sim 37 \%$ of the time (Figure 1). Moreover, the elephants never consistently selected for the less preferred plant species in any combination across all trials (Figure 1).

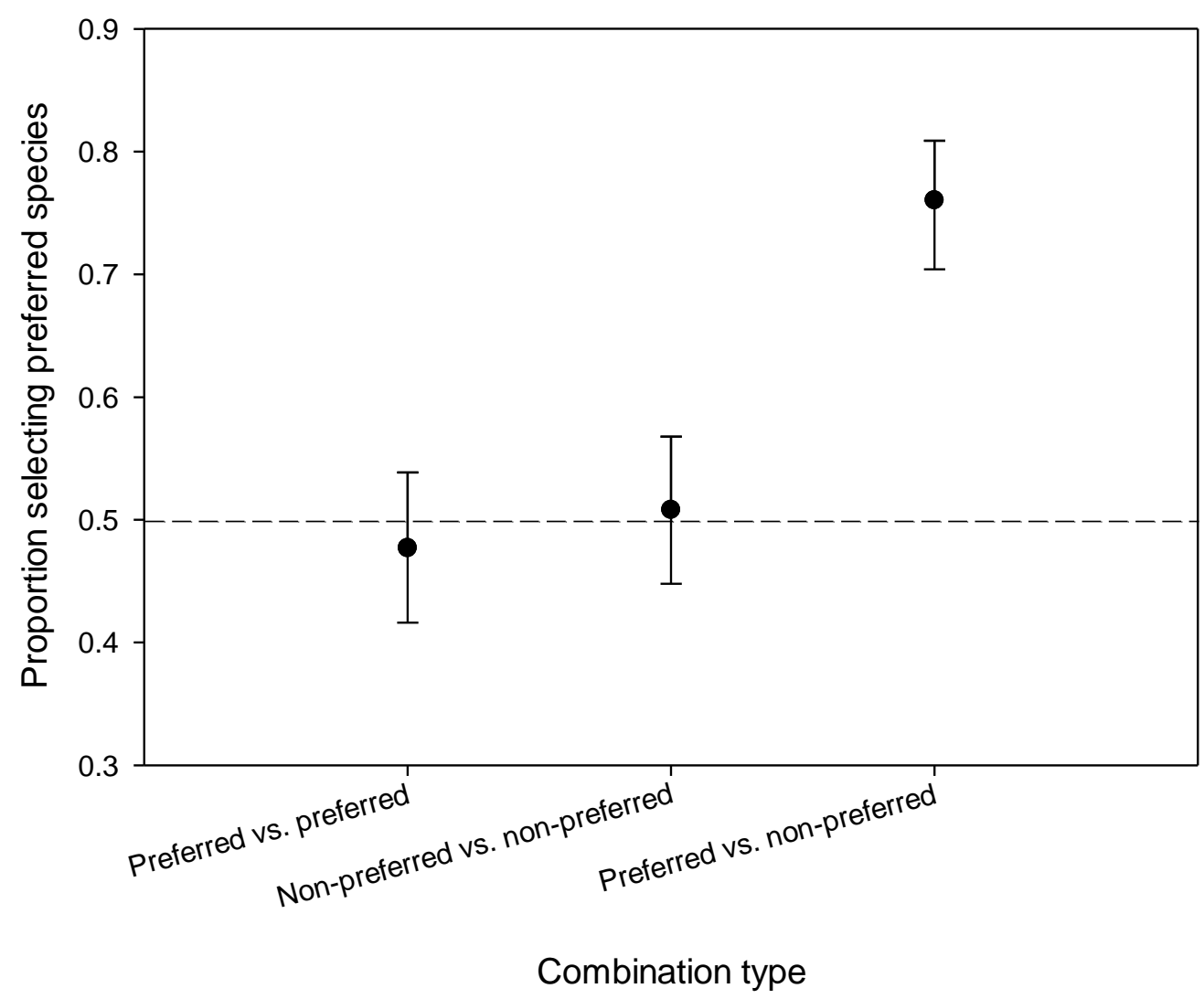

Figure 1: Proportion of elephants selecting the more preferred species as a function of combination type in the in the feeding-station experiment. Marginal means ( $\pm 95 \%$ Confidence Intervals) of the proportion of selection of a given option are plotted. Error bars overlapping the 0.5 expectation (i.e. random selection) indicate no difference in preference.

In the above model, we did not differentiate the 57 combinations between combination types (i.e. two preferred species tested against each other, two non-preferred species tested against each other, or one preferred and one non-preferred species tested against each other), nor did we include the difference in rank between plant species within a combination. Thus, to further explore how these factors influenced choice, we conducted two additional GEEs. When we tested for combination type, we found that this significantly 
influenced elephant preference (GEE: $\chi^{2}=46.444, P<0.0001$; Figure 1). Specifically, when given the choice between two preferred species or two non-preferred species, they showed no significant preference. However, when the elephants were given the choice between a preferred and a non-preferred species, they significantly selected for the preferred species (Figure 1).

In addition to combination type, the difference in rank between species also influenced selection (GEE: $\left.\chi^{2}=509.154, P<0.0001\right)$. Specifically, as the difference in rank increased, the proportion of elephants selecting the preferred option increased (Figure 2). Interestingly, we found that where there was a difference of rank of 1 or 2 places, the elephants did not show a preference for either of the species (i.e. random - 0.5).

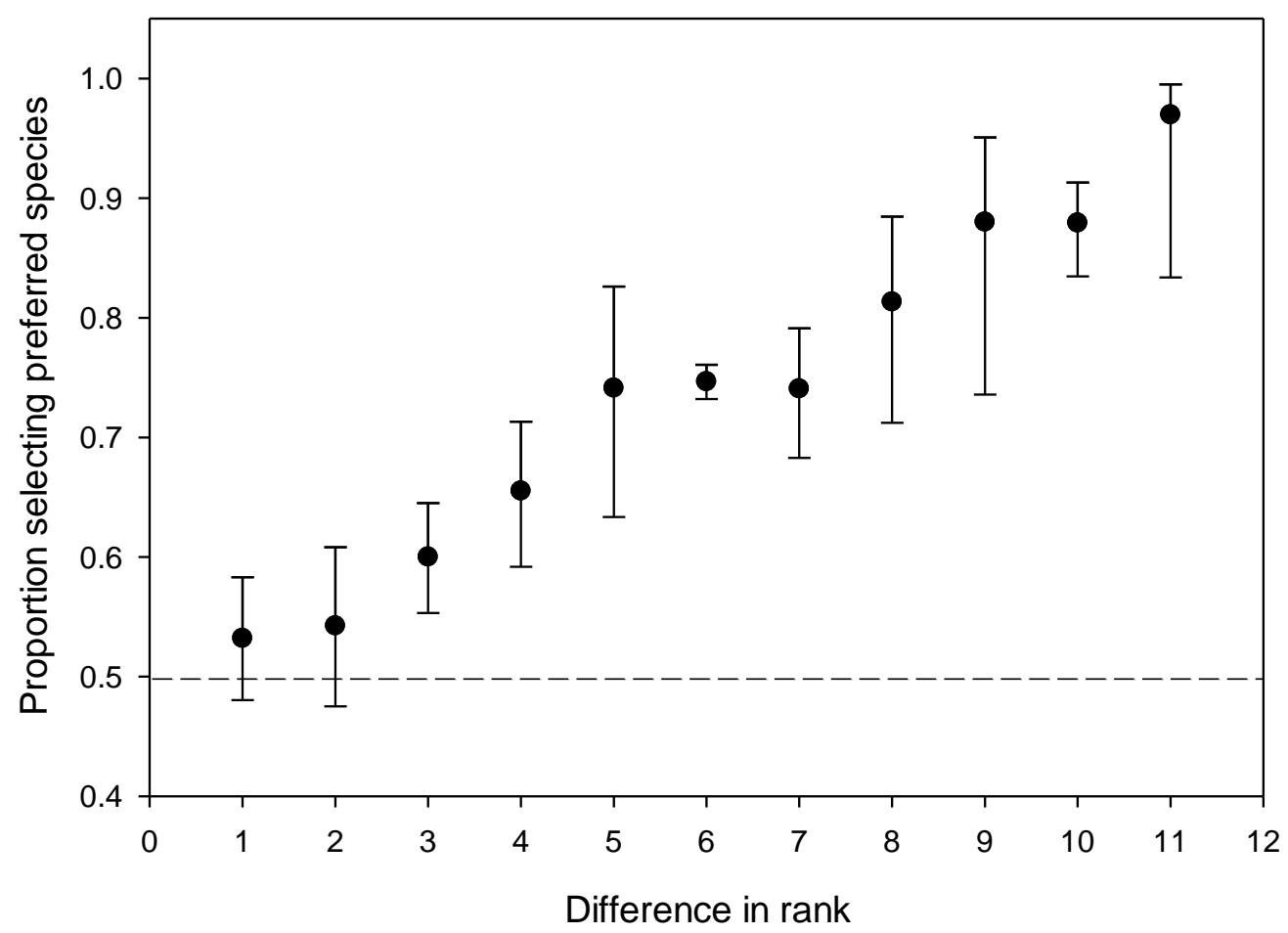

Figure 2: Proportion of elephants selecting the more preferred species as a function of difference in rank between options in the feeding-station experiment. Marginal means ( $\pm 95 \%$ Confidence Intervals) of the proportion of selection of a given option are plotted. Error bars overlapping the 0.5 expectation (i.e. random selection) indicate no difference in preference. 


\section{Between-patch experiment}

The Y-maze experiment revealed that elephants were able to make scent-based decisions over a distance $\sim 7 \mathrm{~m}$ (i.e. simulation of between patches). Across all six combinations that we tested, elephants always selected for the more preferred plant species (GEE: $\chi^{2}=10.372$, $P=0.006)$. Furthermore, elephants differentiated between differently ranked plants and always selected the more preferred plant species (as determined by the acceptability index), regardless of difference in rank $\left(\mathrm{GEE}: \chi^{2}=10.372, P=0.006\right.$; Figure 3$)$.

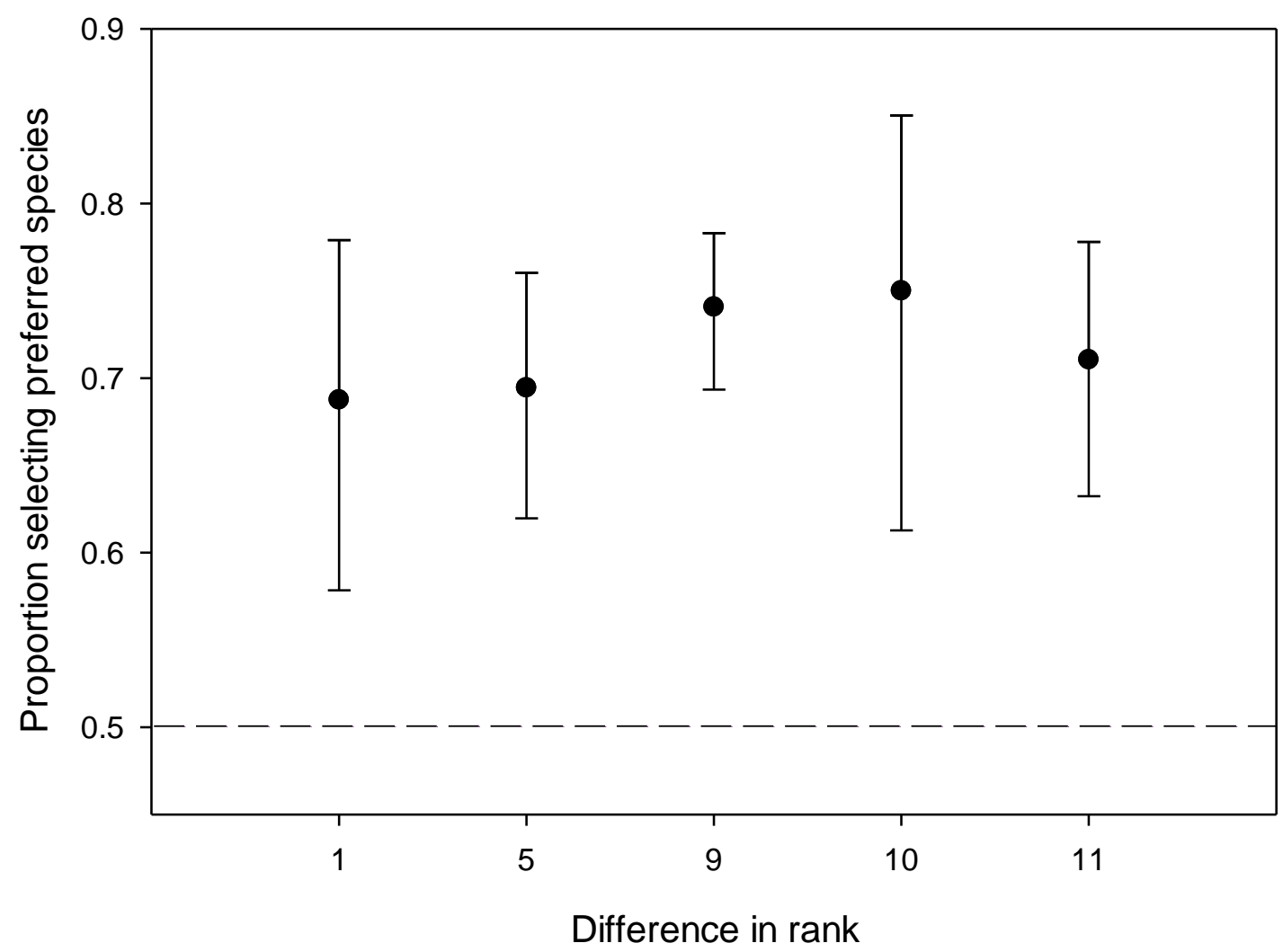

Figure 3: Proportion of elephants selecting the more preferred species as a function of difference in rank between options in the between-patch experiment. Marginal means $( \pm 95 \%$ Confidence Intervals $)$ of the proportion of selection of a given option are plotted. Error bars overlapping the 0.5 expectation (i.e. random selection) would indicate no difference in preference. 


\section{Discussion}

There are a number of ways in which animals could potentially assess vegetation characteristics such as biomass, availability, and nutritional quality when making foraging decisions. The mechanisms that mammalian herbivores could use include direct sampling of vegetation, visual examination of available resources, and assessment of olfactory cues emitted from the vegetation (Krueger, Laycock, \& Price, 1974; Krebs \& McCleery, 1984; Fortin, 2003; Klaassen et al., 2006; Stutz et al., 2015; Stutz et al., 2016; Stutz et al., 2018). The latter has seldom been considered in studies of mammalian foraging behaviour. Our experiments show that African elephants are able to detect, distinguish, and use plant odour to make foraging decisions across different spatial scales. This suggests that odour is a key component that African elephants use when making diet selections.

Many foragers seek to maximise nutritional intake. However, the energy used to move between patches diminishes the energy gained from feeding within patches (Schoener, 1971; Bergman, Fryxell, Gates, \& Fortin, 2001). Our findings suggest that elephants are using olfactory cues to identify good patches and assess the quality of tree species contained within patches. By identifying what species are available in a feeding station (e.g. within a tree cluster) and between patches (e.g. between tree-clumps) via olfaction, free-ranging elephants could then use this information to determine the location of target high-quality/preferred species within a patch as well as to decide which patches to visit, and potentially how long to stay in a given patch.

In our study, elephants selected for their more preferred plant species more frequently across two spatial scales based on the odour emitted by the plants. Interestingly, when we examined selection at the feeding-station scale, we found that the elephants only showed significant preference for an option when choices were between a preferred and a nonpreferred species. This is unexpected because within each of the preferred and non-preferred 
categories, there was a range of preference in AIs (Appendix Table A1). For the preferred category (comprised of both preferred and principle species), the AIs have a very broad range from $0.28-0.87$ of preference, while for the non-preferred plant species, the AIs have a smaller range $(<0.2)$ of preference. Although dietary preference varies, the index we formed suggests that even within the preferred and non-preferred categories, the elephants should theoretically still show preference for one of the options.

The lack of preference between two preferred or two non-preferred species at the feeding-station scale occurred despite the ability of the elephants to differentiate plant species based on odour. The sense of smell of African elephants is superior to that of domestic dogs (Miller et al., 2015), which is better than the olfactory detection of many current GC-MS instruments (Harper, Almirall, \& Furton, 2005). The lack of differentiation could be due to a number of reasons. Firstly, plants within each preference category (i.e. preferred and nonpreferred) are all so similar nutritionally that when faced with the choice between two items from the same preference category, the elephants show no preference due to the similarities. However, this is unlikely because we have shown elsewhere that plant species within the same preference category are not nutritionally similar (Schmitt, 2017). Secondly, ranking plant species as a method for determined preference does not necessarily account for nonlinear patterns in selection (see: Bedoya-Pérez, Issa, Banks, \& McArthur, 2014b). Thirdly, the elephants' lack of preference could be explained by the potential presence of deleterious compounds, such as tannins, alkaloids, or monoterpenes. As a result, the elephants may be using a dietary mixing strategy (Freeland \& Janzen, 1974; Westoby, 1974) where they limit the intake of any deleterious plant secondary metabolites by mixing the non-preferred plant species they consume during the trials. Dietary mixing to avoid ingesting a non-preferred plant species is common in mammalian herbivores (Rogosic, Estell, Skobic, Martinovic, \& Maric, 2006; Papachristou, Dziba, Villalba, \& Provenza, 2007; Copani, Hall, Miller, Priolo, 
\& Villalba, 2013). However, it is unlikely that dietary mixing played a large role in the lack of preference between a rank difference of 1 and 2 because we took a number of measures to remove this as an influencing factor in our experimental design. For example, prior to conducting any of our trials, the elephants were allowed to forage naturally for 1 hour to ensure that hunger levels would not influence foraging choices. Moreover, due to the elephants not being fully satiated during our experiments, it is unlikely that the small trunkful sizes (35 g) used in the choice experiments would be enough to overload the elephants' intake of any one plant secondary metabolite and therefore base their selection on the avoidance of a specific plant secondary metabolite. Considering the combination of these factors, it is unlikely that avoidance of specific plant secondary metabolites would drive the results we obtained. Thus, we believe that our results are an appropriate reflection of the elephants' abilities to discriminate between the olfactory cues of the different plant species.

Finally, the lack of selection within categories could stem from the difference in scales at which our diet-preference data were collected and selection trials were run. Because the scale at which we collected diet-preference data was much larger than the feeding-station scale, our rankings may not perfectly match the elephants' preferences at smaller spatial scales. The elephants may change their tactics to feed less selectively at larger spatial scales when the energetic costs to travel to the next food item outweigh the nutritional benefits (Murray, 1991). In contrast, selectivity might increase at a smaller spatial scale, reflecting the lower energetic costs involved in diet selections at that scale. Consistent with this, we found that as the difference in rank between two plant species increased at the feeding-station scale, the overall selection for the more favoured option increased (i.e., more elephants selected the preferred plant species). This suggests that the elephants made diet selections based on the increasing profit gained by selecting the higher ranking item. However, this selection was significant only when the rank difference was two or more. This significant difference in 
selection may also be a reflection of our experimental design — with a rank difference of one and two the elephants were making selections largely within the two preference categories (i.e. plants within the same category were tested against each other). A possible explanation is that elephants cannot differentiate between closely ranked plants. However, when plants were separated by one or two ranks, but spanned the different categories (preferred vs nonpreferred), elephants always selected the preferred plant. This suggests that elephants do indeed have the ability to differentiate between plant species that are closely ranked. Thus, the lack of selection when plants are in the same category is likely driven the lack of difference in nutritional intake at $35 \mathrm{~g}$ of plant material that was presented to the elephants.

At a small scale, odour is a key information source that herbivores can use to identify target species, even when the odour or sight of the favoured species is masked by less preferred options (Stutz et al., 2015). For example, a recent study showed that swamp wallabies (Wallabia bicolor) are able to find a preferred plant species even when it is hidden inside a stand of less desirable options (Stutz et al., 2015). The wallabies actively sniffed the air around the stand of plants, and eventually located the target species hidden inside the stand. Similarly, reindeer (Rangifer tarandus) were able to distinguish good and poor lichen sources via olfactory cues below $90 \mathrm{~cm}$ of snow (Helle, 1984).

It is unlikely that foragers would be omniscient about the location and availability of resources in their environment (Bazely, 1988; Wilmshurst et al., 1995; Ward, 2010). Therefore, using odour cues, elephants would be able to locate potential food items across multiple spatial scales. Our findings are consistent with the idea that elephants are capable of using odour cues to make foraging decisions at distances beyond their body length $(\sim 7 \mathrm{~m})$ to select a patch. Moreover, because we only used a small trunkful of vegetation (35 g) in our experiments, the distance from which elephants and other herbivores could locate trees is likely much greater. Nevertheless, elephants also use odour cues to make feeding decisions 
between plants at the feeding station scale. These foraging decisions based on plant odours could be a result of a conditioned response to past post-ingestive consequences (Villalba et al., 2015). Several past studies have found that mammalian herbivores have learned to avoid certain plants due to negative postingestive feedback (Provenza \& Balph, 1987; Provenza et al., 1990; Kyriazakis et al., 1998; Bedoya-Pérez et al., 2014a). Thus, it is possible that foragers can identify these plants by their smell and make the link between the smell of these plants and the negative consequences of eating them. Our experimental design did not test for the role of conditioned flavour aversions in elephant diet choice directly. However, it is likely that the elephants in our study learned to associate odours with postingestive costs and incorporated this into their diet selections. Given our results, odour cues could be a tool that numerous other browsing species use to make forging decisions.

\section{Acknowledgements}

We thank S. Hensman, M. Hensman, J. Crosby, and the staff at Adventures with Elephants for allowing us to conduct our study on their premises. We also thank S. Johnson for the use of his laboratory space and GC-MS. Additionally, we thank K. Stears and S. Johnson for their statistical advice. This research was supported by the National Research Foundation of South Africa (grant numbers: 90448, 90691, 97262, \& 77582) and the Gay Langmuir Bursary from the University of KwaZulu-Natal, School of Life Sciences.

\section{References}

Anderson, M. J. (2001). A new method for non-parametric multivariate analysis of variance. Austral Ecology, 26, 32-46. 
Baluska, F., \& Ninkovic, V. (2010). Plant Communication from an Ecological Perspective. Berlin, Germany: Springer

Barton, K. E., \& Koricheva, J. (2010). The ontogeny of plant defense and herbivory: characterizing general patterns using meta-analysis. American Naturalist, 175, 481493.

Bazely, D. (1988). Foraging behaviour of sheep (Ovis aries L.) grazing on swards of perennial ryegrass (Lolium perenne L.). Unpublished $\mathrm{PhD}$ thesis, University of Oxford, Oxford, United Kingdom.

Bedoya-Pérez, M. A., Isler, I., Banks, P. B., \& McArthur, C. (2014a). Roles of the volatile terpene, 1, 8-cineole, in plant-herbivore interactions: a foraging odor cue as well as a toxin? Oecologia, 174, 827-837.

Bedoya-Pérez, M. A., Issa, D. D., Banks, P. B., \& McArthur, C. (2014b). Quantifying the response of free-ranging mammalian herbivores to the interplay between plant defense and nutrient concentrations. Oecologia, 175, 1167-1177.

Bell, W. J. (1990). Searching behavior patterns in insects. Annual Review of Entomology, 35, 447-467.

Bell, W. J. (2012). Searching Behaviour: The Behavioural Ecology of Finding Resources. Dordrecht, Netherlands: Springer Science \& Business Media.

Bergman, C. M., Fryxell, J. M., Gates, C. C., \& Fortin, D. (2001). Ungulate foraging strategies: Energy maximizing or time minimizing? Journal of Animal Ecology, 70, 289-300.

Charnov, E. L. (1976). Optimal foraging, the marginal value theorem. Theoretical Population Biology, 9, 129-136. 
Clark, C. M., Cleland, E. E., Collins, S. L., Fargione, J. E., Gough, L., Gross, K. L., et al. (2007). Environmental and plant community determinants of species loss following nitrogen enrichment. Ecology Letters, 10, 596-607.

Cohen, Y., Pastor, J., \& Moen, R. (1999). Bite, chew, and swallow. Ecological Modelling, $116,1-14$.

Coley, P. D., Bryant, J. P., \& Chapin III, F. S. (1985). Resource availability and plant antiherbivore defense. Science, 230, 895-899.

Cooper, S. M., \& Owen-Smith, N. (1985). Condensed tannins deter feeding by browsing ruminants in a South African savanna. Oecologia, 67, 142-146.

Copani, G., Hall, J. O., Miller, J., Priolo, A., \& Villalba, J. J. (2013). Plant secondary compounds as complementary resources: Are they always complementary? Oecologia, 172, 1041-1049.

Crane, K. K., Mosley, J. C., Mosley, T. K., Frost, R. A., Smith, M. A., Fuller, W. L., et al. (2016). Elk foraging site selection on foothill and mountain rangeland in spring. Rangeland Ecology \& Management, 69, 319-325.

De Knegt, H. J., Groen, T. A., Van De Vijver, C. A. D. M., Prins, H. H. T., \& Van Langevelde, F. (2008). Herbivores as architects of savannas: Inducing and modifying spatial vegetation patterning. Oikos, $117,543-554$.

Entsu, S., Dohi, H., \& Yamada, A. (1992). Visual acuity of cattle determined by the method of discrimination learning. Applied Animal Behaviour Science, 34, 1-10.

Finnerty, P. B., Stutz, R. S., Price, C. J., Banks, P. B., \& McArthur, C. (2017). Leaf odour cues enable non-random foraging by mammalian herbivores. Journal of Animal Ecology, 86, 1317-1328.

Fortin, D. (2003). Searching behavior and use of sampling information by free-ranging bison (Bos bison). Behavioral Ecology and Sociobiology, 54, 194-203. 
Freeland, W. J., \& Janzen, D. H. (1974). Strategies in herbivory by mammals: The role of plant secondary compounds. American Naturalist, 108, 269-289.

Harborne, J. B. (1991). The chemical basis of plant defence. In R. T. Palo \& C. T. Robbins (Eds.), Plant Defenses Against Mammalian Herbivory (pp. 45). Boca Raton, Florida, USA: CRC Press.

Hardin, J. W. (2005). Generalized Estimating Equations (GEE). London, U.K.: Wiley Online Library.

Harper, R. J., Almirall, J. R., \& Furton, K. G. (2005). Identification of dominant odor chemicals emanating from explosives for use in developing optimal training aid combinations and mimics for canine detection. Talanta, 67, 313-327.

Helle, T. (1984). Foraging behaviour of the semi-domestic reindeer (Rangifer tarandus L.) in relation to snow in Finnish Lapland Report from Kevo Subarctic Research Station (Vol. 19, pp. 35-47): Kevo Subarctic Research Station, Utsjoki, Finland.

Hosoi, E., Rittenhouse, L., Swift, D., \& Richards, R. (1995). Foraging strategies of cattle in a Y-maze: influence of food availability. Applied Animal Behaviour Science, 43, 189196.

Houston, A. I., \& McNamara, J. M. (2014). Foraging currencies, metabolism and behavioural routines. Journal of Animal Ecology, 83, 30-40.

Illius, A. W., \& Gordon, I. J. (1990). Constraints on diet selection and foraging behaviour in mammalian herbivores. In R. N. Hughes (Ed.), Behavioural Mechanisms of Food Selection (pp. 369-393). Berlin, Germany: Springer.

Illius, A. W., \& Gordon, I. J. (1993). Diet selection in mammalian herbivores: Constraints and tactics. In R. Hughes (Ed.), An Interdisciplinary Approach To Foraging Behavior. (pp. 157-181). Oxford, U.K.: Blackwell Scientific Publishing. 
Jacobs, G. H., Deegan, J. F., \& Neitz, J. (1998). Photopigment basis for dichromatic color vision in cows, goats, and sheep. Visual Neuroscience, 15, 581-584.

Kariñho-Betancourt, E., Agrawal, A. A., Halitschke, R., \& Núñez- Farfán, J. (2015). Phylogenetic correlations among chemical and physical plant defenses change with ontogeny. New Phytologist, 206, 796-806.

Klaassen, R. H. G., Nolet, B. A., van Gils, J. A., \& Bauer, S. (2006). Optimal movement between patches under incomplete information about the spatial distribution of food items. Theoretical Population Biology, 70, 452-463.

Kovats, E. S. (1965). Gas Chromatographic Characterization of Organic Substances in the Retention Index System (Vol. 1). New York, USA: Marcel Dekker.

Krebs, J. R., \& McCleery, R. H. (1984). Individual optimization in behavioural ecology. In J. R. Krebs \& N. B. Davies (Eds.), Behavioural Ecology: An Evolutionary Approach (Vol. 91-12). Oxford, U.K.: Blackwell Scientific.

Krueger, W. C., Laycock, W. A., \& Price, D. A. (1974). Relationships of taste, smell, sight, and touch to forage selection. Journal of Range Management, 27, 258-262.

Kyriazakis, I., Anderson, D., \& Duncan, A. (1998). Conditioned flavour aversions in sheep: the relationship between the dose rate of a secondary plant compound and the acquisition and persistence of aversions. British Journal of Nutrition, 79, 55-62.

Miller, A. K., Hensman, M. C., Hensman, S., Schultz, K., Reid, P., Shore, M., et al. (2015). African elephants (Loxodonta africana) can detect TNT using olfaction: Implications for biosensor application. Applied Animal Behaviour Science, 171, 177-183.

Morgan, K. V., Hurly, T. A., Martin, L., \& Healy, S. D. (2016). Presentation order affects decisions made by foraging hummingbirds. Behavioral Ecology and Sociobiology, 70, $21-26$. 
Murray, M. G. (1991). Maximizing energy retention in grazing ruminants. Journal of Animal Ecology, 60, 1029-1045.

Niinemets, Ü., Loreto, F., \& Reichstein, M. (2004). Physiological and physicochemical controls on foliar volatile organic compound emissions. Trends in Plant Science, 9, $180-186$.

Owen-Smith, N., \& Chafota, J. (2012). Selective feeding by a megaherbivore, the African elephant (Loxodonta africana). Journal of Mammalogy, 93, 698-705.

Owen-Smith, N., \& Cooper, S. M. (1987). Assessing food preferences of ungulates by acceptability indices. Journal of Wildlife Management, 51, 372-378.

Owen-Smith, N., Fryxell, J. M., \& Merrill, E. H. (2010). Foraging theory upscaled: The behavioural ecology of herbivore movement. Philosophical Transactions of the Royal Society of London B: Biological Sciences, 365, 2267-2278.

Papachristou, T. G., Dziba, L. E., Villalba, J. J., \& Provenza, F. D. (2007). Patterns of diet mixing by sheep offered foods varying in nutrients and plant secondary compounds. Applied Animal Behaviour Science, 108, 68-80.

Peñuelas, J., \& Llusià, J. (2004). Plant VOC emissions: Making use of the unavoidable. Trends in Ecology and Evolution, 19, 402-404.

Pietrzykowski, E., McArthur, C., Fitzgerald, H., \& Goodwin, A. (2003). Influence of patch characteristics on browsing of tree seedlings by mammalian herbivores. Journal of Applied Ecology, 40, 458-469.

Piggins, D., \& Phillips, C. (1996). The eye of the domesticated sheep with implications for vision. Animal Science, 62, 301-308.

Pretorius, Y., Stigter, J. D., de Boer, W. F., van Wieren, S. E., de Jong, C. B., de Knegt, H. J., et al. (2012). Diet selection of African elephant over time shows changing optimization currency. Oikos, 121, 2110-2120. 
Provenza, F. D., \& Balph, D. (1987). Diet learning by domestic ruminants: Theory, evidence and practical implications. Applied Animal Behaviour Science, 18, 211-232.

Provenza, F. D., Burritt, E. A., Clausen, T., Bryant, J., Reichardt, P., \& Distel, R. A. (1990). Conditioned flavor aversion: A mechanism for goats to avoid condensed tannins in blackbrush. American Naturalist, 136, 810-828.

Pyke, G. H., Pulliam, R. H., \& Charnov, E. L. (1977). Optimal foraging: A selective review of theory and tests. Quarterly Review of Biology, 52, 137-154.

Raguso, R. A. (2008). Wake up and smell the roses: The ecology and evolution of floral scent. Annual Review of Ecology, Evolution, and Systematics, 549-569.

Rhoades, D. F. (1979). Evolution of plant chemical defense against herbivores Herbivores: Their Interaction With Secondary Plant Metabolites (pp. 3-54). New York, USA: Academic Press.

Rogosic, J., Estell, R. E., Skobic, D., Martinovic, A., \& Maric, S. (2006). Role of species diversity and secondary compound complementarity on diet selection of Mediterranean shrubs by goats. Journal of Chemical Ecology, 32, 1279-1287.

Ruedenauer, F. A., Spaethe, J., \& Leonhardt, S. D. (2016). Hungry for quality-individual bumblebees forage flexibly to collect high-quality pollen. Behavioral Ecology and Sociobiology, 70, 1-9.

Rutter, S. M., Orr, R. J., Yarrow, N. H., \& Champion, R. A. (2004). Dietary preference of dairy cows grazing ryegrass and white clover. Journal of Dairy Science, 87, 13171324.

Schmitt, M. H. (2017). The influences of plant secondary metabolites on the forgaging behaviour and carrying capacities for the African elephant, Loxodonta africana. Unpublished PhD thesis, University of KwaZulu-Natal, Pietermaritzburg, South Africa. 
Schmitt, M. H., Ward, D., \& Shrader, A. M. (2016). Incorporating secondary metabolites, tannin-binding proteins, and diet breadth into carrying-capacity models for African elephants. Ecological Modelling, 332, 8-18.

Schoener, T. W. (1971). Theory of feeding strategies. Annual Review of Ecology and Systematics, 11, 369-404.

Senft, R., Coughenour, M., Bailey, D., Rittenhouse, L., Sala, O., \& Swift, D. (1987). Large herbivore foraging and ecological hierarchies. BioScience, 37, 789-799.

Shipley, L. A. (2007). The influence of bite size on foraging at larger spatial and temporal scales by mammalian herbivores. Oikos, 116, 1964-1974.

Shrader, A. M., Bell, C., Bertolli, L., \& Ward, D. (2012). Forest or the trees: At what scale do elephants make foraging decisions? Acta Oecologica, 42, 3-10.

Shuttleworth, A. (2016). Smells like debauchery: The chemical composition of semen-like, sweat-like and faintly foetid floral odours in Xysmalobium (Apocynaceae: Asclepiadoideae). Biochemical Systematics and Ecology, 66, 63-75.

Shuttleworth, A., \& Johnson, S. D. (2009). A key role for floral scent in a wasp-pollination system in Eucomis (Hyacinthaceae). Annals of Botany, 103, 715-725.

Stutz, R. S., Banks, P. B., Dexter, N., \& McArthur, C. (2015). Herbivore search behaviour drives associational plant refuge. Acta Oecologica, 67, 1-7.

Stutz, R. S., Banks, P. B., Proschogo, N., \& McArthur, C. (2016). Follow your nose: Leaf odour as an important foraging cue for mammalian herbivores. Oecologia, 182, 643651.

Stutz, R. S., Croak, B. M., Proschogo, N., Banks, P. B., \& McArthur, C. (2018). Olfactory and visual plant cues as drivers of selective herbivory. Oikos, 126, doi:10.1111/oik.03422. 
Tholl, D. (2006). Terpene synthases and the regulation, diversity and biological roles of terpene metabolism. Current Opinion in Plant Biology, 9, 297-304.

Villalba, J., Provenza, F., Catanese, F., \& Distel, R. (2015). Understanding and manipulating diet choice in grazing animals. Animal Production Science, 55, 261-271.

Wang, M. (2014). Generalized Estimating Equations in Longitudinal Data Analysis: A Review and Recent Developments. Advances in Statistics, 2014, 303728.

Ward, D. (1992). The role of satisficing in foraging theory. Oikos, 63, 312-317.

Ward, D. (2010). A parsimonious optimal foraging model explaining mortality patterns in Serengeti wildebeest. Ecological Modelling, 221, 2406-2408.

Ward, D., \& Saltz, D. (1994). Forging at different spatial scales: Dorcas gazelles foraging for lilies in the Negev Desert. Ecology, 75, 48-58.

Ward, D., Shrestha, M. K., \& Golan-Goldhirsh, A. (2012). Evolution and ecology meet molecular genetics: Adaptive phenotypic plasticity in two isolated Negev desert populations of Acacia raddiana at either end of a rainfall gradient. Annals of Botany, $109,247-255$.

Westoby, M. (1974). An analysis of diet selection by large generalist herbivores. American Naturalist, 108, 290-304.

Wilmshurst, J. F., Fryxell, J. M., \& Hudson, R. J. (1995). Forage quality and patch choice by wapiti (Cervus elaphus). Behavioral Ecology, 6, 209-217. 


\section{Appendix}

Table A1: Acceptability Index (AI) of preferred and non-preferred plant species.

\begin{tabular}{lcccc}
\hline Species & Acceptability & $\begin{array}{c}\text { \# Times } \\
\text { Consumed }\end{array}$ & $\begin{array}{c}\text { \# Times } \\
\text { Encountered }\end{array}$ & AI \\
\hline Viscum combreticola & Novel Preferred & NA & NA & NA \\
Pappea capensis & Preferred & 71 & 82 & 0.87 \\
Dombeya rotundifolia & Preferred & 45 & 61 & 0.74 \\
Terminalia sericea & Preferred & 92 & 132 & 0.70 \\
Combretum zeyheri & Preferred & 134 & 205 & 0.65 \\
Grewia monticola & Principal & 171 & 339 & 0.50 \\
Euclea crispa & Principal & 155 & 559 & 0.28 \\
Vitex rehmannii & Non-preferred & 15 & 78 & 0.19 \\
Searsia pyroides & Non-preferred & 18 & 98 & 0.18 \\
Searsia lancea & Non-preferred & 52 & 410 & 0.13 \\
Euclea undulata & Non-preferred & 3 & 83 & 0.04 \\
Olea europaea & Non-preferred & 0 & 222 & 0.00 \\
\hline
\end{tabular}


Table A2: Results from pairwise ANOSIM contrasts of odour profiles from each species in every combination presented to the elephants.

\begin{tabular}{|c|c|c|}
\hline Combinations & $\begin{array}{c}\mathbf{R} \\
\text { Statistic }\end{array}$ & $\begin{array}{c}\text { Significance } \\
\text { Level (\%) }\end{array}$ \\
\hline Pappea capensis $(\mathrm{P})$ vs Euclea crispa $(\mathrm{P})$ & 0.446 & 0.0002 \\
\hline Pappea capensis $(\mathrm{P})$ vs Combretum zeyheri $(\mathrm{P})$ & 0.485 & 0.0002 \\
\hline Pappea capensis $(\mathrm{P})$ vs Dombeya rotundifolia $(\mathrm{P})$ & 0.299 & 0.004 \\
\hline Combretum zeyheri $(\mathrm{P})$ vs Euclea crispa $(\mathrm{P})$ & 0.371 & 0.0002 \\
\hline Combretum zeyheri $(\mathrm{P})$ vs Dombeya rotundifolia $(\mathrm{P})$ & 0.324 & 0.0006 \\
\hline Terminalia sericea $(\mathrm{P})$ vs Euclea crispa $(\mathrm{P})$ & 0.493 & 0.0002 \\
\hline Terminalia sericea $(\mathrm{P})$ vs Pappea capensis $(\mathrm{P})$ & 0.485 & 0.0002 \\
\hline Terminalia sericea $(\mathrm{P})$ vs Combretum zeyheri $(\mathrm{P})$ & 0.435 & 0.0003 \\
\hline Terminalia sericea $(\mathrm{P})$ vs Dombeya rotundifolia $(\mathrm{P})$ & 0.406 & 0.0003 \\
\hline Grewia monticola $(\mathrm{P})$ vs Euclea crispa $(\mathrm{P})$ & 0.54 & 0.0002 \\
\hline Grewia monticola $(\mathrm{P})$ vs Pappea capensis $(\mathrm{P})$ & 0.605 & 0.0002 \\
\hline Grewia monticola $(\mathrm{P})$ vs Combretum zeyheri $(\mathrm{P})$ & 0.565 & 0.0003 \\
\hline Grewia monticola $(\mathrm{P})$ vs Terminalia sericea $(\mathrm{P})$ & 0.474 & 0.001 \\
\hline Grewia monticola $(\mathrm{P})$ vs Dombeya rotundifolia $(\mathrm{P})$ & 0.472 & 0.0008 \\
\hline Dombeya rotundifolia $(\mathrm{P})$ vs Euclea crispa $(\mathrm{P})$ & 0.499 & 0.0002 \\
\hline Euclea undulata (NP) vs Vitex rehmannii (NP) & 0.999 & 0.0002 \\
\hline Euclea undulata (NP) vs Searsia pyroides(NP) & 1 & 0.0002 \\
\hline Searsia lancea (NP) vs Euclea undulata (NP) & 0.998 & 0.0002 \\
\hline Searsia lancea $(\mathrm{NP})$ vs Vitex rehmannii $(\mathrm{NP})$ & 0.983 & 0.0002 \\
\hline Searsia lancea (NP) vs Searsia pyroides (NP) & 0.735 & 0.0002 \\
\hline Searsia lancea (NP) vs Olea europaea (NP) & 0.973 & 0.0002 \\
\hline Searsia pyroides (NP) vs Vitex rehmannii (NP) & 0.994 & 0.0002 \\
\hline Olea europaea (NP) vs Euclea undulata (NP) & 1 & 0.0002 \\
\hline Olea europaea (NP) vs Vitex rehmannii (NP) & 1 & 0.0002 \\
\hline Olea europaea (NP) vs Searsia pyroides (NP) & 0.988 & 0.0002 \\
\hline Euclea undulata(NP) vs Euclea crispa (P) & 0.79 & 0.0002 \\
\hline Searsia lancea $(\mathrm{NP})$ vs Euclea crispa $(\mathrm{P})$ & 0.608 & 0.0002 \\
\hline Searsia lancea $(\mathrm{NP})$ vs Dombeya rotundifolia $(\mathrm{P})$ & 0.793 & 0.0002 \\
\hline Pappea capensis (P) vs Euclea undulata (NP) & 0.826 & 0.0002 \\
\hline Pappea capensis (P) vs Searsia lancea (NP) & 0.756 & 0.0002 \\
\hline Pappea capensis (P) vs Vitex rehmannii (NP) & 0.928 & 0.0002 \\
\hline Pappea capensis $(\mathrm{P})$ vs Searsia pyroides $(\mathrm{NP})$ & 0.813 & 0.0002 \\
\hline Pappea capensis (P) vs Olea europaea (NP) & 0.511 & 0.0005 \\
\hline Combretum zeyheri (P) vs Euclea undulata (NP) & 0.907 & 0.0002 \\
\hline Combretum zeyheri (P) vs Searsia lancea (NP) & 0.71 & 0.0002 \\
\hline Combretum zeyheri $(\mathrm{P})$ vs Vitex rehmannii $(\mathrm{NP})$ & 0.941 & 0.0002 \\
\hline Combretum zeyheri $(\mathrm{P})$ vs Searsia pyroides $(\mathrm{NP})$ & 0.628 & 0.0002 \\
\hline Combretum zeyheri $(\mathrm{P})$ vs Olea europaea (NP) & 0.459 & 0.0005 \\
\hline Viscum combreticola $(\mathrm{P})$ vs Euclea undulata (NP) & 0.859 & 0.0002 \\
\hline Viscum combreticola $(\mathrm{P})$ vs Olea europaea (NP) & 0.74 & 0.0002 \\
\hline Vitex rehmannii $(\mathrm{NP})$ vs Euclea crispa $(\mathrm{P})$ & 0.789 & 0.0002 \\
\hline Terminalia sericea $(\mathrm{P})$ vs Euclea undulata $(\mathrm{NP})$ & 0.978 & 0.0002 \\
\hline
\end{tabular}


Terminalia sericea (P) vs Searsia lancea (NP)

$0.85 \quad 0.0002$

Terminalia sericea $(\mathrm{P})$ vs Vitex rehmannii $(\mathrm{NP})$

$1 \quad 0.0002$

Terminalia sericea $(\mathrm{P})$ vs Searsia pyroides (NP)

$0.839 \quad 0.0002$

Terminalia sericea $(\mathrm{P})$ vs Olea europaea (NP)

$0.575 \quad 0.0003$

Grewia monticola (P) vs Euclea undulata (NP)

$0.912 \quad 0.0002$

Grewia monticola (P) vs Searsia lancea (NP)

$0.763 \quad 0.0002$

Grewia monticola $(\mathrm{P})$ vs Vitex rehmannii (NP)

$0.934 \quad 0.0002$

Grewia monticola $(\mathrm{P})$ vs Searsia pyroides (NP)

$0.773 \quad 0.0002$

Grewia monticola (P) vs Olea europaea (NP)

$0.68 \quad 0.0003$

Searsia pyroides (NP) vs Euclea crispa $(\mathrm{P})$

$0.633 \quad 0.0002$

Olea europaea (NP) vs Euclea crispa (P)

$0.63 \quad 0.0003$

Olea europaea $(\mathrm{NP})$ vs Dombeya rotundifolia $(\mathrm{P})$

$0.411 \quad 0.0006$

Dombeya rotundifolia (P) vs Euclea undulata (NP)

$0.819 \quad 0.0002$

Dombeya rotundifolia $(\mathrm{P})$ vs Vitex rehmannii $(\mathrm{NP})$

$0.822 \quad 0.0002$

Dombeya rotundifolia $(\mathrm{P})$ vs Searsia pyroides (NP)

0.758

0.0002

$\mathrm{P}=$ preferred, $\mathrm{NP}=$ Non-preferred 
Table A3: Volatile organic compounds identified in all plant odour samples used for these studies.

\begin{tabular}{|c|c|c|}
\hline Compound & Kovats & $\begin{array}{c}\text { ID } \\
\text { Criteria }\end{array}$ \\
\hline \multicolumn{3}{|l|}{ Aliphatics } \\
\hline \multicolumn{3}{|l|}{ Alkanes } \\
\hline Decane & 1159 & $\mathrm{C}$ \\
\hline Undecane & 1187 & $\mathrm{C}$ \\
\hline Dodecane & 1225 & $\mathrm{C}$ \\
\hline \multicolumn{3}{|l|}{ Alcohols } \\
\hline Hexan-1-ol & 1340 & $\mathrm{C}$ \\
\hline (Z)-Hex-3-en-1-ol & 1380 & A \\
\hline (E)-Hex-2-en-1-ol & 1383 & A \\
\hline Octan-2-ol & 1395 & A \\
\hline 1-Heptanol & 1431 & A \\
\hline (E)-Oct-2-en-1-ol & 1602 & A \\
\hline Nonanol & 1653 & A \\
\hline Decanol & 1761 & A \\
\hline Hexadecan-1-ol & 2409 & A \\
\hline \multicolumn{3}{|l|}{ Aldehydes } \\
\hline (E)-Hex-2-enal & 1248 & A \\
\hline (E)-Oct-2-enal & 1414 & A \\
\hline (E,E)-Hepta-2,4-dienal & 1483 & A \\
\hline Decanal & 1487 & $\mathrm{C}$ \\
\hline (E)-Non-2-enal & 1522 & A \\
\hline (Z)-Dec-2-enal & 1648 & A \\
\hline Dodecanal & 1709 & A \\
\hline \multicolumn{3}{|l|}{ Ketones } \\
\hline Heptan-2-one & 1219 & A \\
\hline 6-Methylheptan-2-one & 1253 & A \\
\hline Octan-2-one & 1286 & $\mathrm{~A}$ \\
\hline 3,5-Dimethyloctan-2-one & 1342 & $\mathrm{~B}$ \\
\hline Nonan-2-one & 1376 & A \\
\hline Decan-2-one & 1473 & A \\
\hline Hexane-2,5-dione & 1489 & A \\
\hline Undecan-2-one & 1587 & A \\
\hline Dodecan-2-one & 1704 & A \\
\hline \multicolumn{3}{|l|}{ Esters } \\
\hline Amyl acetate & 1213 & A \\
\hline Methyl caproate & 1221 & A \\
\hline Hexyl acetate & 1279 & $\mathrm{C}$ \\
\hline (Z)-Hex-3-en-1-yl acetate & 1312 & $\mathrm{C}$ \\
\hline (E)-Hex-2-en-1-yl acetate & 1321 & A \\
\hline Heptyl acetate & 1359 & A \\
\hline (Z)-Hex-3-en-1-yl propanoate & 1368 & A \\
\hline Ethyl octanoate & 1415 & A \\
\hline (Z)-Hex-en-1-yl butyrate & 1440 & A \\
\hline (Z)-Hex-3-en-1-yl isovalerate & 1451 & A \\
\hline
\end{tabular}


Acids

2-Methyl propanoic acid

Butanoic acid

1623

Pentanoic acid

4-Methylpentanoic acid

Hexanoic acid

1811

1866

Hex-5-enoic acid

1934

2-Ethylhexanoic acid

1975

Hept-6-enoic acid

Octanoic acid

Oct-7-enoic acid

Nonanoic acid

1521

Benzaldehyde

Methyl benzoate

1521

1619

A

Phenylacetaldehyde

1644

1683

p-Methoxystyrene

1687

2-Hydroxybenzaldehyde

Methyl salicylate

Phenylethyl acetate

1830

A

C

Guaiacol

1882

A

A

B

Benzyl alcohol

1907

Benzyl 3-methylbutanoate

1920

Phenylethyl alcohol

1945

p-Cresol

2124

C

m-Cresol

2131

B

(Z)-Hex-3-en-1-yl benzoate

2177

2215

Eugenol

2219

A

Ethyl 4-ethoxybenzoate

Benzoic acid

C-5 Branched compounds

Isovaleric acid

1670

A

A

C

2-Methylbutanoic acid

\section{Terpenoids}

Monoterpenes

$\alpha$-Pinene

Sabinene

$\beta$-Pinene

Eucalyptol

Limonene

(Z)-Ocimene

o-Cymene (could be p-cymene) 
2,6-Dimethylocta-3,7-diene-2,6-diol

$1437 \quad$ A

(Z)-Linalool oxide (furanoid)

1449

C

Linalool

1525

Pinocarvone

1562

$\alpha$-Terpineol

1692

endo-Borneol

1700

1744

Carvone

1809

Myrtenol

1817

(E,E)-2,6-Dimethylocta-3,5,7-triene-2-ol

1849

(Z)-p-Mentha-6,8-dien-2-ol

1867

C

p-Cymen-8-ol

1910

A

(Z)-p-Mentha-1(7),8-dien-2-ol

2166

2,6-Dimethylocta-1,7-diene-3,6-diol

2257

C

Carvacrol

A

Sesquiterpenes

$\alpha$-Copaene

1471

A

$\beta$-Bourbonene

1506

A

$\alpha$-Bergamotene

1571

A

(Z)- $\beta$-Caryophyllene

1571

(E)- $\beta$-Caryophyllene

1587

Humulene

1666

A

A

B

Germacrene D

1710

A

$\alpha$-Muurolene

1723

A

$\beta$-Caryophyllene oxide

2031

Spathulenol

2172

1438

m/z: 204*,105,119,95,91,67

1455

m/z: 204*, 105,43,91,53,55,72,79

1466

m/z: 204*,105,119,93,120,91,92

1479

m/z: 204*,161, 43, 119, 41, 105

1568

m/z: 204*,120,105,91,161,79,93

1588

m/z: 204*,105,161,91,109,119,81

1607

m/z: 204*,91,105,93,107,79,119

1632

$\mathrm{m} / \mathrm{z}: 204^{*}, 105,161,119,77,136$

1646

$\mathrm{m} / \mathrm{z}: 204 *, 91,93,105,107,79$

1654

m/z: 204*,92,91,55,83,105,70

1664

m/z: 204*,91,93,105,79,119,107

1683

m/z: 204*,91,43,93,119,84,82

1689

$\mathrm{m} / \mathrm{z}: 204^{*}, 105,91,93,119,121,122$

1701

m/z: 204*,136,121,91,43,105,93

1758

m/z: $204 *, 91,119,55,105,41,161$

1772

m/z: 204*,91,105,119,161,93,79

2198

Irregular terpenes

6-Methyl-5-hepten-2-ol

1437

A

A

A

A

C

A

A

A

C

A

Sabina ketone

1634

A

Geranyl acetone

1873

A

Miscellaneous cyclic compounds 


\begin{tabular}{|c|c|}
\hline 2-Furfural & 1451 \\
\hline 5,5-Dimethyl-2(5H)-furanone & 1606 \\
\hline Dihydro-5-methyl-2(3H)-furanone & 1614 \\
\hline Butyrolactone & 1637 \\
\hline 4-Hexanolide & 1717 \\
\hline$\delta$-Hexalactone & 1824 \\
\hline$\gamma$-Heptalactone & 183 \\
\hline 4-Octanolide & 1955 \\
\hline$\gamma$-Nonalactone & 2079 \\
\hline Indole & 2486 \\
\hline \multicolumn{2}{|l|}{ Unknowns } \\
\hline $\mathrm{m} / \mathrm{z}: 106,91,43,55,71$ & 1192 \\
\hline $\mathrm{m} / \mathrm{z}: 43,67,41,57,68,86$ & 1239 \\
\hline $\mathrm{m} / \mathrm{z}: 150^{*}, 69,41,81,79,82,53$ & 1303 \\
\hline $\mathrm{m} / \mathrm{z}: 128^{*}, 43,99,55,112,70,71$ & 1304 \\
\hline m/z: 56,55,70,57,69,43 & 1353 \\
\hline $\mathrm{m} / \mathrm{z}: 136^{*}, 121,91,105,79,119,55$ & 1359 \\
\hline $\mathrm{m} / \mathrm{z}: 95,43,82,109,67,111$ & 1401 \\
\hline $\mathrm{m} / \mathrm{z}: 43,57,98,55,58,71$ & 1406 \\
\hline $\mathrm{m} / \mathrm{z}: 53,47,71,41,55,81$ & 1413 \\
\hline $\mathrm{m} / \mathrm{z}: 43,80,79,39,41,77,81$ & 1416 \\
\hline $\mathrm{m} / \mathrm{z}: 56,57,55,70,41,69,43$ & 1431 \\
\hline $\mathrm{m} / \mathrm{z}: 81,110,39,53,41,57$ & 1450 \\
\hline m/z: 79,110,95,77,94,67 & 1450 \\
\hline $\mathrm{m} / \mathrm{z}: 43,71,112,41,27$ & 1554 \\
\hline $\mathrm{m} / \mathrm{z}: 123^{*}, 57,82,67,43,81,41$ & 1556 \\
\hline $\mathrm{m} / \mathrm{z}: 41,55,43,57,82,71$ & 1559 \\
\hline mz: 99,43,57,71,100,42,55 & 1570 \\
\hline $\mathrm{m} / \mathrm{z}: 83,55,81,95,41$ & 1577 \\
\hline $\mathrm{m} / \mathrm{z}: 112^{*}, 83,55,57,84$ & 1592 \\
\hline $\mathrm{m} / \mathrm{z}: 41,43,57,55,71$ & 1604 \\
\hline $\mathrm{m} / \mathrm{z}: 97,43,69,42,45,41$ & 1616 \\
\hline m/z: 55,83,97,69,41,57,56 & 1633 \\
\hline m/z: 42,41,56,86,39,43 & 1635 \\
\hline $\mathrm{m} / \mathrm{z}: 43,55,58,71,95,85,99$ & 1670 \\
\hline $\mathrm{m} / \mathrm{z}: 43,95,58,71,55,85,41$ & 1674 \\
\hline $\mathrm{m} / \mathrm{z}: 126^{*}, 111,55,67,43,98,71,83$ & 1675 \\
\hline $\mathrm{m} / \mathrm{z}: 82,81,43,54,39,55,53$ & 1679 \\
\hline $\mathrm{m} / \mathrm{z}: 117^{*}, 91,90,43,89,65,118$ & 1680 \\
\hline $\mathrm{m} / \mathrm{z}: 98^{*}, 43,55,41,39,70$ & 1731 \\
\hline $\mathrm{m} / \mathrm{z}: 96,43,95,67,68,81$ & 175 \\
\hline $\mathrm{m} / \mathrm{z}: 134 *, 119,91,65,120,92,98$ & 1796 \\
\hline m/z: 71,43,99,41,59,53 & 1811 \\
\hline $\mathrm{m} / \mathrm{z}: 119,43,109,143,91$ & 1815 \\
\hline $\mathrm{m} / \mathrm{z}: 85,57,41,29,43$ & 1998 \\
\hline $\mathrm{m} / \mathrm{z}: 57,85,39,41,43,55,31$ & 200 \\
\hline m/z: 99, 43, 71, 87, 114 & 201 \\
\hline $\mathrm{m} / \mathrm{z}: 55,81,82,41,67,79$ & 20 \\
\hline
\end{tabular}


m/z: 74, 87, 41, 43, 55

$\mathrm{m} / \mathrm{z}: 43,95,67,55,41,107$

m/z: 126*,98,55,83,11,84,43

m/z: 55,43,41,57,82,96

$\mathrm{m} / \mathrm{z}: 43,58,71,57,59,41$

m/z: 133,91,43,148,105,79

m/z: 136,91,79,93,41,69

m/z: 93,91,105,107,109,95

$\mathrm{m} / \mathrm{z}: 83,97,57,55,69,43$
2057

2099

2140

2163

2167

2285

2350

2382

2594

ID criteria: A = library match was confirmed with published retention index (Kovats), $\mathrm{B}=$ library match only, C = library match confirmed with both a published retention index and injection of a synthetic standard under identical conditions to the samples. Unknowns (including unidentified sesquiterpenes) are presented with the molecular mass first (tentatively identified from the mass spectrum, so not always known) indicated by a * followed by the base peak and remaining fragments in decreasing order of abundance. 


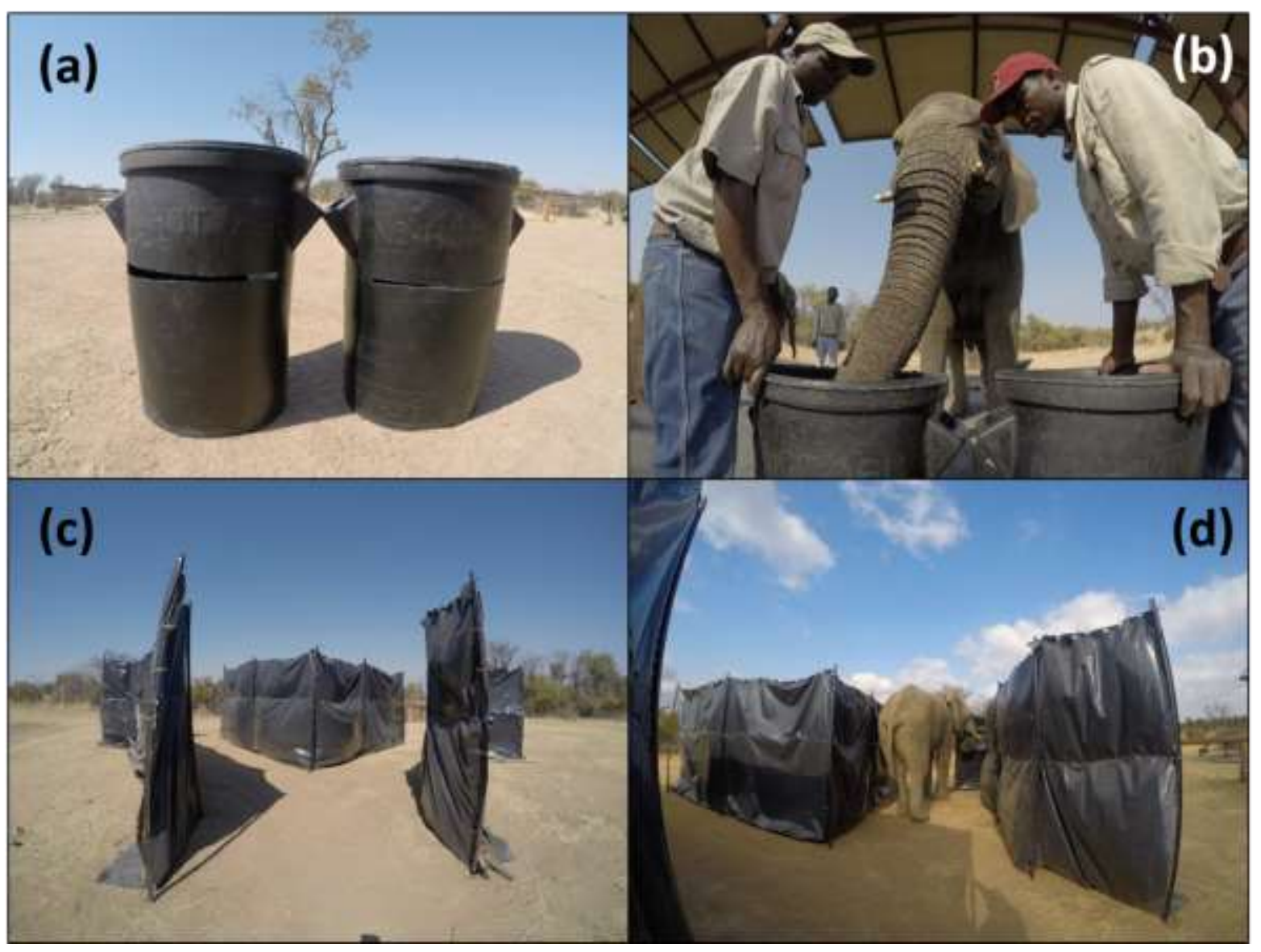

Figure A1: A representation of both the feeding-station and between-patch experiments. Panels (a) and (b) illustrate the feeding stations composed of two bins (i.e. species choice), while (c) and (d) show the Y-maze used in the between-patch selection experiment. Slots in panel (a) indicate where the PVC boards were inserted. 


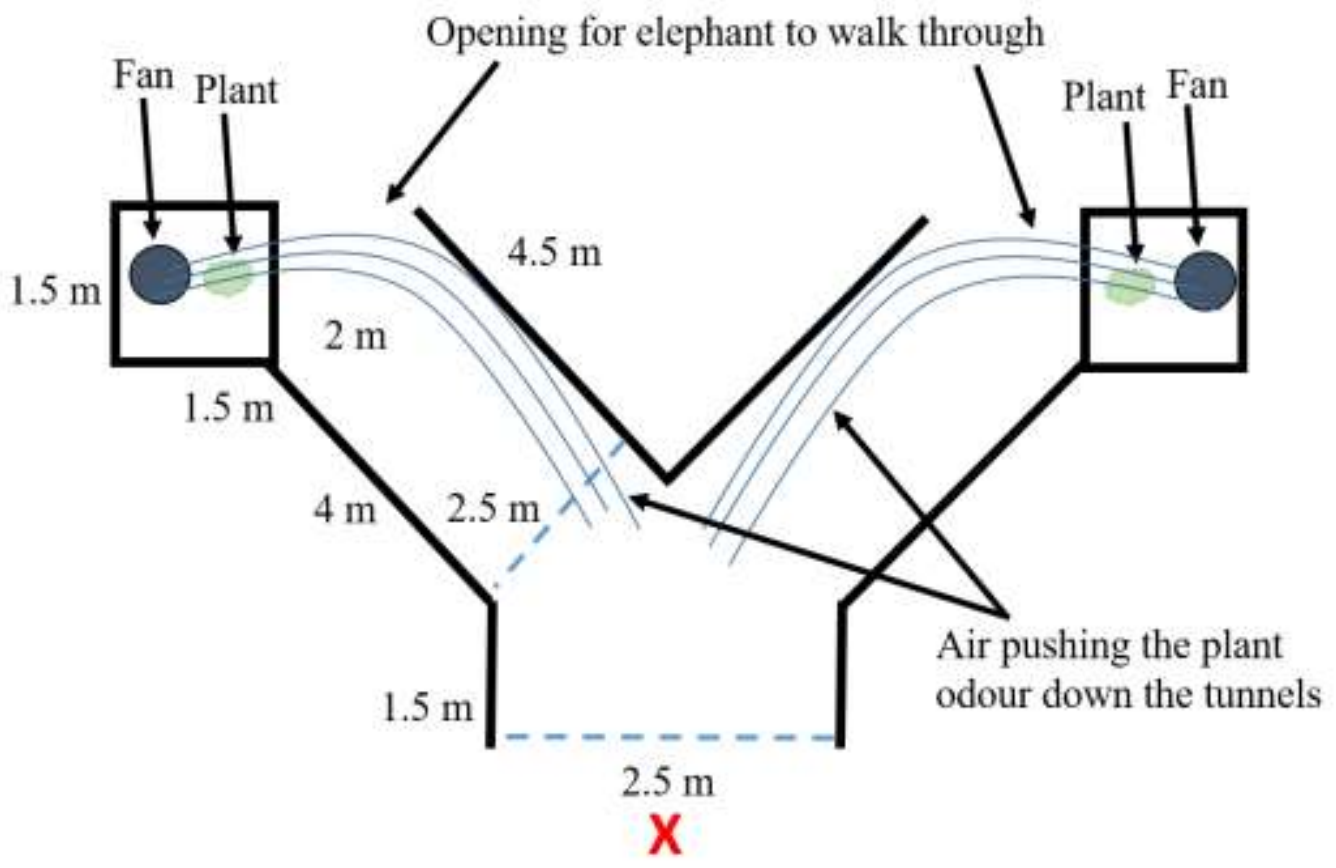

Figure A2: Schematic of the Y-maze. Red "X" indicates the location where the elephants were instructed to stop and smell the air from each arm of the maze and then make their foraging decision. 